\title{
Successful Management of Fetal Hydrothorax associated with Hydrops
}

\author{
${ }^{1}$ Erasmo Huertas, ${ }^{2}$ Adelita Híjar, ${ }^{3}$ Igor Huerta, ${ }^{4}$ José C Elias, ${ }^{5}$ Armando Florez, ${ }^{6}$ Luis M Gomez
}

\begin{abstract}
We report a case of massive unilateral hydrothorax diagnosed at 18 weeks' gestation in a fetus with normal karyotype. The fetus was affected severely by hydrops from 22 weeks. Initially, we performed a pleurodesis, but due to worsening hydrothorax evolving into hydrops, we proceeded with insertion of a transplacental thoracoamniotic shunt. Improvement was evident from 1 week after the procedure followed by resolution of hydrothorax for the remainder of the pregnancy. After a cesarean delivery at 37 weeks, the neonate required prolonged neonatal intensive care unit stay. He was discharged when he was 2 months old and has remained stable until the present time.
\end{abstract}

Keywords: Fetal hydrothorax, Hydrops, Pleural effusion, Prenatal treatment, Thoracoamniotic shunt.

How to cite this article: Huertas E, Híjar A, Huerta I, Elias JC, Florez A, Gomez LM. Successful Management of Fetal Hydrothorax associated with Hydrops. Donald School J Ultrasound Obstet Gynecol 2018;12(2):145-147.

Source of support: Nil

Conflict of interest: None

\section{INTRODUCTION}

Fetal congenital hydrothorax or pleural effusion is a rare condition. ${ }^{1,2}$ While mild effusions remain stable or resolve, large effusions are associated with mass effect leading to mediastinal shift, pulmonary hypoplasia, hydrops, and/ or abnormal cardiac function or arrhythmias. ${ }^{2-4}$ Fetuses presenting with hydrops and polyhydramnios due to large pleural effusion are at risk for preterm delivery and perinatal death due to pulmonary hypoplasia or heart failure. ${ }^{5}$

We present a case of unilateral large pleural effusion associated with hydrops in a fetus with anterior placenta

\footnotetext{
${ }^{1}$ Chief and Associate Professor, ${ }^{2-6}$ Clinical Assistant

${ }^{1}$ Department of Perinatology, Clínica San Felipe, Lima, Peru Department of Obstetrics and Gynecology, Universidad Nacional Mayor de San Marcos, Lima, Perú

${ }^{2-5}$ Department of Perinatology, Clínica San Felipe, Lima, Peru

${ }^{6}$ Division of Maternal Fetal Medicine, INOVA Health System Perinatal Associates of Northern Virginia, Virginia, USA

Corresponding Author: Erasmo Huertas, Chief and Associate Professor, Department of Perinatology, Clínica San Felipe Lima, Peru; Department of Obstetrics and Gynecology Universidad Nacional Mayor de San Marcos, Lima, Perú, Phone: +51999143288, e-mail: erasmohuertas@hotmail.com
}

successfully managed with transplacental thoracoamniotic shunting.

\section{CASE REPORT}

A healthy 29-year-old primigravida was referred to our center at 18 weeks due to fetal unilateral hydrothorax. Her pregnancy course had been uncomplicated before diagnosis. At 19 weeks, we confirmed a large left pleural effusion with right mediastinal shift; we did not note other structural malformations. We performed an amniocentesis with a 22-gauge needle. After collecting amniotic fluid, we performed a thoracentesis retrieving $26 \mathrm{~mL}$ of yellow-tinged fluid. The pleural fluid showed no bacteria by Gram staining, leukocyte 300/ $\mu \mathrm{L}$ with $77 \%$ lymphocytes, protein $1.63 \mathrm{gm} / \mathrm{dL}$, and cholesterol $31 \mathrm{mg} / \mathrm{dL}$. Chromosomal karyotype was reported as normal (male fetus). Maternal serology showed no acute toxoplasma, cytomegalovirus or herpes infection, and was negative for indirect Coombs and Venereal Disease Research Laboratory test. At 22 weeks, a repeat ultrasound showed massive hydrothorax, subcutaneous edema, and ascites (fetal hydrops) along with polyhydramnios (Fig. 1).

Due to the anterior location of the placenta, we deferred thoracoamniotic shunting and opted for pleurodesis carried out at 23 weeks: After aspirating $100 \mathrm{~mL}$ of pleural fluid, we injected $15 \mathrm{~mL}$ of fresh maternal blood into the pleural cavity under sonographic guidance using a 20-gauge needle. One week later, we

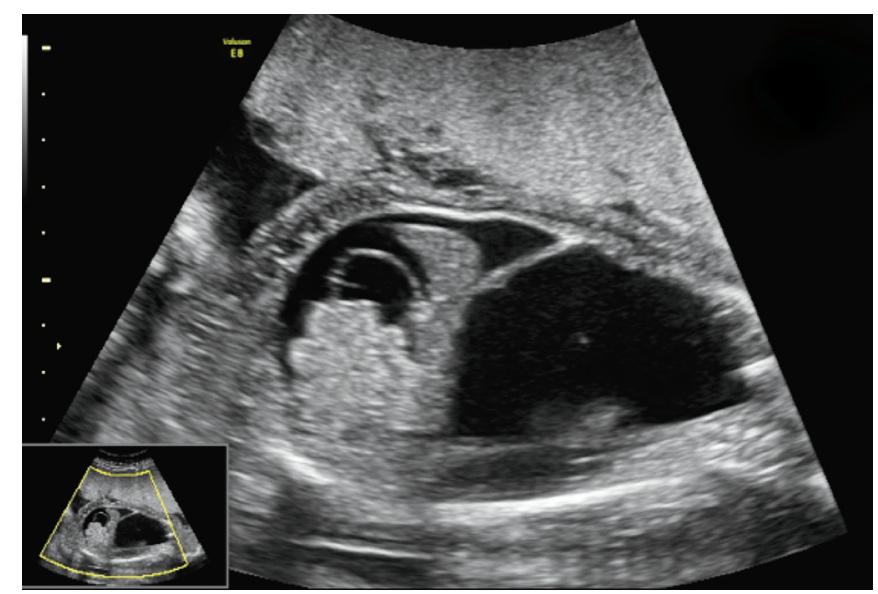

Fig. 1: Preoperative ultrasound image at 22 weeks' gestation showing massive hydrothorax with subcutaneous edema and ascites (hydrops) 


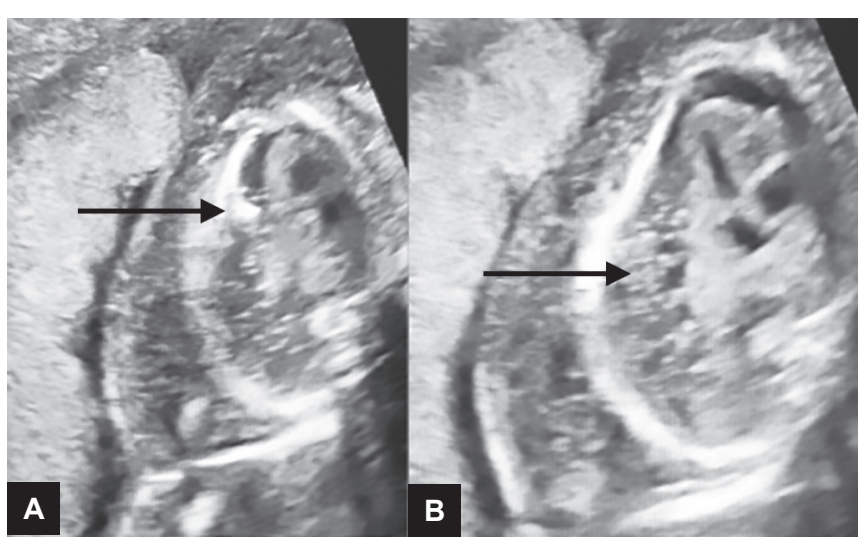

Fig. 2A and B: Pleurodesis at 23 weeks' gestation. The picture on the left shows the echogenic tip (arrow) of the needle entering the fetal thorax. The picture on the right shows observed blood regurgitation (arrow)

noted accumulation of pleural fluid with worsening hydrothorax (Fig. 2).

At 24 weeks, the fetus became severely hydropic and showed intermittent episodes of bradycardia. After reviewing the risks and benefits with the patient, we obtained consent to perform a transplacental fetal thoracoamniotic shunting using a silicone double-pigtail catheter inserted through a $3 \mathrm{~mm}$ introducer (Harrison shunt, Cook Medical, Inc., Spencer, IN, USA) placed in the left pleural space under ultrasound guidance (Fig. 3). The procedure was uncomplicated. One week later, the fetal hydrothorax had decreased considerably. At 33 weeks, there was only residual laminar left hydrothorax while ascites and subcutaneous edema had resolved (Fig. 4).

After administering late preterm antenatal corticosteroids, we delivered a 2,950-gm newborn at 37 weeks via cesarean. Apgar scores were 9 at 1 and 5 minutes. During delivery, the pigtail catheter was displaced inadvertently from the fetal thorax before it could be clamped. This led to neonatal pneumothorax requiring mechanical ventilation. The newborn developed pulmonary hypertension that resolved with medical management. After 6 weeks of hospitalization, he was discharged in stable condition.

At the present time, the infant remains stable achieving normal psychomotor and anthropometric milestones (Fig. 5).
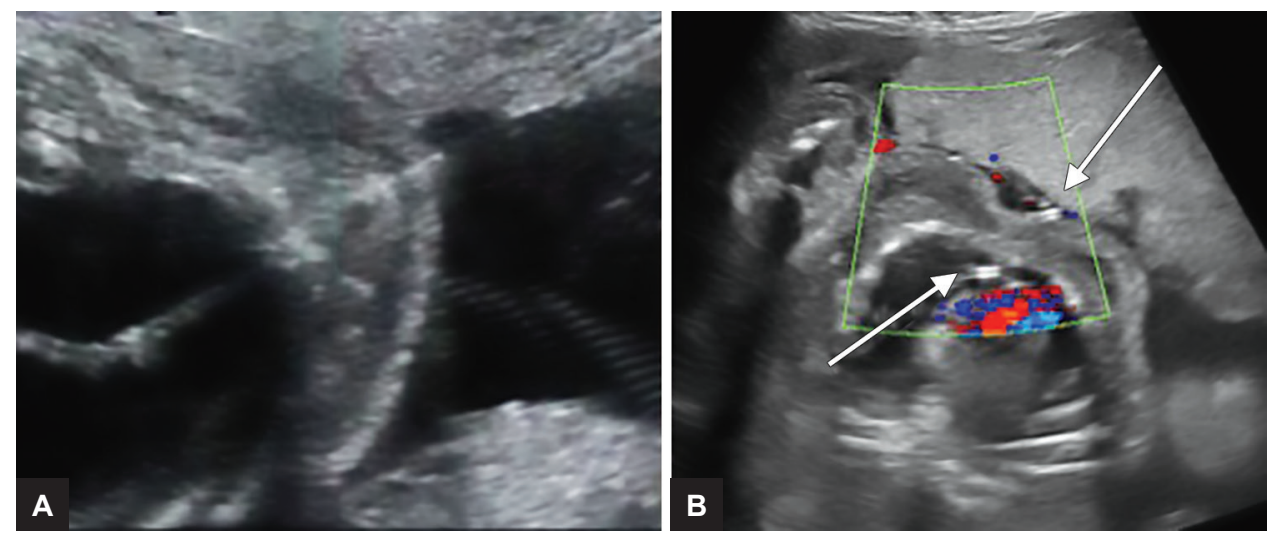

Figs $3 \mathbf{A}$ and $\mathbf{B}$ : On the left picture, we observe the needle inside fetal thorax after crossing the placenta. On the right, the white arrows point to both ends of the pigtail catheter: One inside the thorax and the other in the amniotic cavity

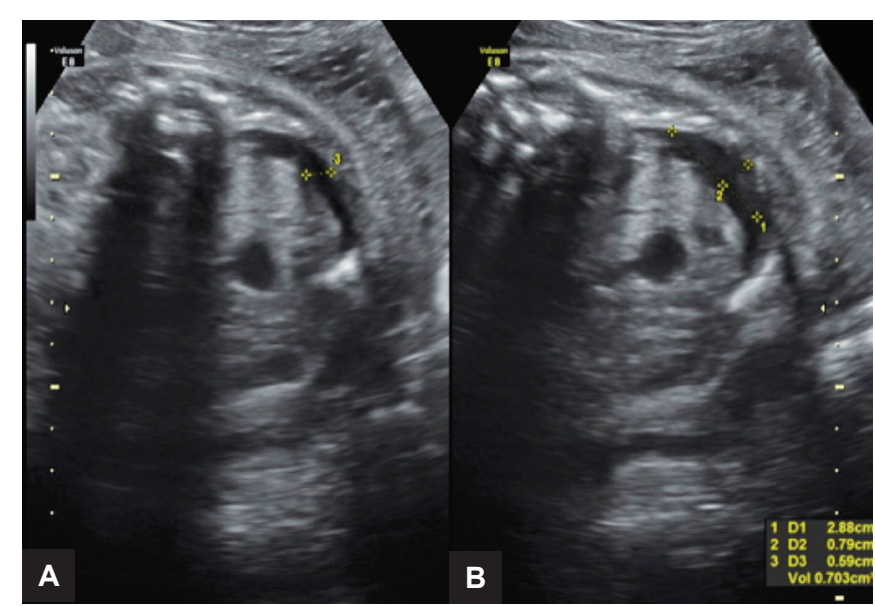

Fig. 4: At 32 weeks' gestation, the fetal thorax shows residual linear effusion in the left thorax posttransplacental thoracoamniotic shunting

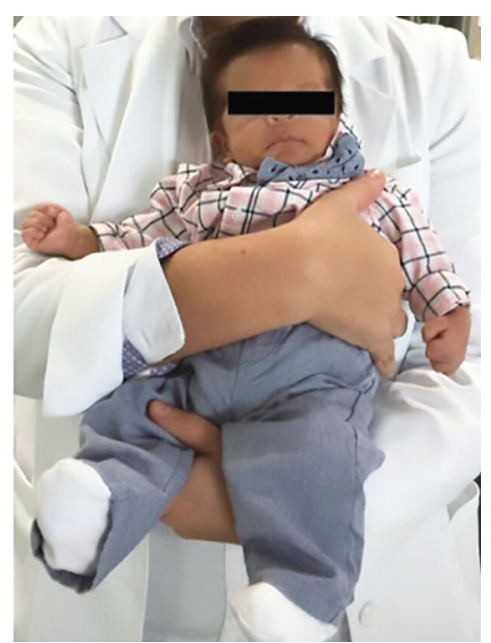

Fig. 5: Newborn at 2 months in stable condition after hospital discharge 


\section{DISCUSSION}

Fetal hydrothorax refers to pleural effusion, which can be either primary or secondary. Its incidence ranges from 1:10,000 to $1: 15,000$ pregnancies. ${ }^{1}$ Primary effusions are due to lymphatic leakage resulting in raised intrathoracic pressure that may progress to hydrops. ${ }^{6}$ The most common form of primary pleural effusion is chylothorax. Chylothorax is diagnosed by cytological and biochemical analysis of the fluid aspirate: Yellow-colored, with lymphocyte count $>70-80 \%$, and fluid protein and cholesterol lower than their serum counterparts. ${ }^{2,3}$ The prognosis depends largely on the underlying cause. Perinatal outcomes are worsened by associated malformations (as much as $25 \%$ ) and aneuploidy (7-12\% of all cases). ${ }^{7,8}$ The majority of cases are mild, ${ }^{9}$ but severe cases ensue when the fluid expands over $>50 \%$ of the thorax. Severe pleural effusion is associated with elevated perinatal morbidity and mortality which are much higher in the presence of fetal hydrops. ${ }^{10}$ Hydrops in a fetus with primary hydrothorax carries a poor prognosis, and is an independent predictor of poor outcomes with perinatal mortality rate as high as 50\%.

In our case, the fetal pleural effusion evolved into severe hydrops with episodes of bradycardia. Initially, we managed this case with thoracentesis; however, it did not succeed and the hydrothorax progressed into hydrops. Next, due to the anterior placental location, we performed a pleurodesis, instead of shunting, injecting maternal blood. Pleurodesis was first described in 2001 by Okawa et $\mathrm{al}^{11}$ with good outcomes using OK-432 as the sclerosant agent. Because OK-432 is not free of potential risks, ${ }^{12}$ other clinicians have used maternal blood instead. The first report of pleurodesis with intrapleural injection of maternal blood was reported by Parra et $\mathrm{al}^{13}$ with also good results and less fetal risks. Nonetheless, in our patient, pleurodesis using maternal blood was not successful either and the fetus presented with worsening hydrops and new onset of bradycardia episodes. Next, we opted for transplacental thoracoamniotic shunting performed without any complications leading to resolution of pleural effusion and hydrops and normalization of the fetal heart rate. This technique was described by Seeds and Bowes ${ }^{14}$ for the first time in 1986. Thoracoamniotic shunting is the gold standard therapy for pleural effusion in the setting of hydrops, with a survival rate of 33 to $66 \%$. Rates of success are higher with the use of a double-pigtail catheter. ${ }^{15}$ After shunting placement, close monitoring of the fetus by ultrasound scans is warranted. Although in utero displacement of the catheter has been reported in as much as $23 \%$ of cases, ${ }^{2}$ we did not encounter that problem. Rather, it was at delivery that the catheter dislocated leading to neonatal pneumothorax.

The early response to shunting seen in our case was pivotal because it allowed fetal lung expansion (preventing pulmonary hypoplasia) and restoration of the displaced mediastinal anatomy. We suggest that in cases of diagnosis in the second trimester and large effusions with hydrops, the most appropriate treatment is thoracoamniotic shunt even with an anterior placenta. The mode of delivery can be based on obstetric criteria. Delivery should occur at a tertiary care center with good neonatal support where potentially an ill neonate can have access to an intensive care unit, especially if ventilation support is required as in this case.

\section{REFERENCES}

1. Longaker MT, Laberge JM, Dansereau J, Langer JC, Crombleholme TM, Callen PW, Golbus MS, Harrison MR. Primary fetal hydrothorax: natural history and management. J Pediatr Surg 1989 Jun;24(6):573-576.

2. Gonen R, Degani S, Kugelman A, Abend M, Bader D. Intrapartum drainage of fetal pleural effusion. Prenat Diagn 1999 Dec;19(12):1124-1126.

3. Yinon Y, Kelly E, Ryan G. Fetal pleural effusions. Best Pract Res Clin Obstet Gynaecol 2008 Feb;22(1):77-96.

4. Castillo RA, Devoe LD, Falls G, Holzman GB, Hadi HA, Fadel HE. Pleural effusions and pulmonary hypoplasia. Am J Obstet Gynecol 1987 Nov;157(5):1252-1255.

5. Fresneda MD, Gómez LF, Molina FS, Romero Espinar Y, Padilla MC. Hidrotórax fetal primario: experiencia propia y revisión de la literatura. Diagn Prenat 2012;23(4):167-173.

6. Yinon Y, Grisaru-Granovsky S, Chaddha V, Windrim R, Seaward PG, Kelly EN, Beresovska O, Ryan G. Perinatal outcome following fetal chest shunt insertion for pleural effusion. Ultrasound Obstet Gynecol 2010 Jul;36(1):58-64.

7. Nicolaides KH, Azar GB. Thoraco-amniotic shunting. Fetal Diagn Ther 1990;5(3-4):153-164.

8. Weber AM, Philipson EH. Fetal pleural effusion: a review and meta-analysis for prognostic indicators. Obstet Gynecol 1992 Feb;79(2):281-286.

9. Yumoto Y, Jwa SC, Wada S, Takahashi Y, Ishii K, Kato K, Usui N, Sago H. The outcomes and prognostic factors of fetal hydrothorax associated with trisomy 21. Prenat Diagn 2017 Jul;37(7):686-692.

10. Alkazaleh F, Saleem M, Badran E. Intrathoracic displacement of pleuroamniotic shunt after successful in utero treatment of fetal hydrops secondary to hydrothorax. Case report and review of the literature. Fetal Diagn Ther 2009;25(1):40-43.

11. Okawa T, Takano Y, Fujimori K, Yanagida K, Sato A. A new fetal therapy for chylothorax: pleurodesis with OK-432. Ultrasound Obstet Gynecol 2001 Oct;18(4):376-377.

12. Kim, JE, Lee C, Park KI, Park MS, Namgung R, Park IK. Successful pleurodesis with OK-432 in preterm infants with persistent pleural effusion. Korean J Pediatr 2012 May;55(5):177-180.

13. Parra J, Amenedo M, Muñiz-Díaz E, Ormo F, Simó M, Vega C, Fernandez JG, Senosiain R, Moliner E, Guinovart G. A new successful therapy for fetal chylothorax by intrapleural injection of maternal blood. Ultrasound Obstet Gynecol 2003 Sep;22(3):290-294.

14. Seeds JW, Bowes WA. Results of treatment of severe hydrothorax with bilateral pleuroamniotic catheters. Obstet Gynecol 1986 Oct;68(4):577-580.

15. Smith RP, Illanes S, Denbow ML, Soothill PW. Outcome of fetal pleural effusions treated by thoracoamniotic shunting. Ultrasound Obstet Gynecol 2005 Jul;26(1):63-66. 